\title{
Prevalence of Obesity among School Going Children Attending Paediatrics Outpatient Department of a Private Medical College Hospital at Puducherry
}

\author{
V. Anebaracy ${ }^{1}$, Abhijeet Shrivastava ${ }^{2}$
}

${ }^{1}$ Assistant Professor, Department of Physiology, Sri Lakshmi Narayana Institute of Medical Sciences, Puducherry, India. ${ }^{2}$ Assistant Professor, Department of Paediatrics, Sri Lakshmi Narayana Institute of Medical Sciences, Puducherry, India.

\section{ABSTRACT}

\section{BACKGROUND}

Obesity is one of the most widespread and major problem affecting children in developed as well as developing countries. The prevalence of obesity has doubled in children in the last two decades. Childhood obesity is an important indicator to predict adulthood obesity and its complications. Obesity and overweight in children can lead to complications like hypertension, dyslipidaemia, hypercholesterolemia, diabetes mellitus and coronary artery disease in their adulthood and an increased risk of early morbidity and mortality. We wanted to determine the prevalence of obesity among school going children aged between 6 to 12 years attending the Paediatric OPD and to analyse the factors causing obesity in them.

\section{METHODS}

It was a cross sectional study. The sample size was 3081 children, attending Paediatric Outpatient Department of Sri Lakshmi Narayana Institute of Medical Sciences Hospital at Puducherry from July 2018 to December 2018. Data was collected on age, sex, and socioeconomic status, intake of junk foods, physical activity and parental obesity.

\section{RESULTS}

In our study, prevalence of obesity was more in lower middle class of modified Kuppuswamy scale. We found that there was a significant association between obesity and sedentary lifestyle with a significant $p$ value of 0.015 . There was also a significant association between junk food and obesity with significant $\mathrm{p}$ value of 0.0001. In our study, children who consumed junk foods for more than 4 days a week had greater chances of being obese. There was a significant association between parental obesity and their children being obese.

\section{CONCLUSIONS}

There is a higher prevalence of obesity in children due to lack of physical activity and junk food intake. Hence obesity prevention awareness program should be conducted in schools and lifestyle modification should be reinforced in school going children in order to prevent adulthood obesity complications.

\section{KEY WORDS}

Obesity, Socioeconomic Status, Junk Food, Physical Activity
Corresponding Author: Dr. Abhijeet Shrivastava, \#43, $3^{\text {rd }}$ Main Road, Kumaran Nagar Ext., Lawspet-605008, Pondicherry, India. E-mail: drabhijeetshrivastava@yahoo.com

DOI: $10.14260 / \mathrm{jemds} / 2019 / 680$

Financial or Other Competing Interests: None.

How to Cite This Article:

Anebaracy V, Shrivastava A. Prevalence of obesity among school going children attending paediatrics outpatient department of a private medical college hospital at Puducherry. J. Evolution Med. Dent. Sci. 2019;8(42):3135-3139, DOI: 10.14260/jemds/2019/680

Submission 23-02-2019,

Peer Review 02-10-2019,

Acceptance 09-10-2019,

Published 21-10-2019. 


\section{BACKGROUND}

Obesity is a condition of unusual and excessive fat accumulation in the adipose tissue to the extent that health may be impaired (World health organization [WHO], 1997). ${ }^{1}$ Low level of physical activity, watching TV, and consuming junk/fast foods are associated with a higher prevalence of overweight and obesity. ${ }^{2}$ Childhood obesity has reached epidemic levels in developed as well as in developing countries. Obesity has a significant impact on both physical and psychological health.

The highest prevalence rates of childhood obesity have been observed in developed countries; however its prevalence is increasing in developing countries as well. ${ }^{3}$ Many factors including genetics, hormonal influence, inutero environment, metabolic status, nutrition status of parents, sleep pattern and eating habits are believed to play role in the development of obesity. Increase in the prevalence of childhood obesity is associated with increased potential medical complications especially in their adulthood, like hypertension, coronary artery disease, cerebrovascular accidents, Type 2 Diabetes mellitus, dyslipidaemia, gall stones, premature joint destruction and many others. 4,5 Obesity in childhood and adolescence has been related to an increase in mortality in adulthood on follow up. Hoffman et al observed almost twice the risk of death in adolescents $(>18$ years old) with $\mathrm{BMI}>25 \mathrm{Kg} / \mathrm{m}^{2}$ (Compared to subjects with BMI $<25 \mathrm{Kg} / \mathrm{m}^{2}$ ) during 20 year follow up. ${ }^{6}$ World health organisation has declared obesity as one of the most neglected diseases of significant public health importance.

The 2002 World health report had documented overweight as the fifth most serious risk factor for both developed as well as developing countries. ${ }^{7}$ Evaluation of obesity in childhood is very important because it helps in preventing progression of disease with its associated morbidities in adulthood. The health and dietary behaviours of the children are highly influenced by their parent's level of education and their weight status. ${ }^{8-11}$

Obese parents have a higher risk of having obese children as they provide both genetic and eating environment and the interaction of these influences in the familial patterns of adiposity. ${ }^{12-14}$ Sedentary behaviour characterised by wakeful activities that require little energy expenditure and during prolonged sitting or reclined position along with lack of physical activity is known to influence obesity, poor metabolic and poor psychosocial health. ${ }^{15,16}$ Diet and unhealthy lifestyles are major contributors to obesity.

Obesity has become a public health concern due to its complications. This study was conducted in the age group between 6 to 12 years, attending Paediatric outpatient Department of Sri Lakshmi Narayana Institute of Medical Sciences hospital, Puducherry to determine the prevalence of obesity and their association with risk factors like socioeconomic status, intake of junk foods, physical activity and parental obesity.

\section{METHODS}

The study was a cross sectional study done at Sri Lakshmi Narayana Institute of medical sciences hospital, Puducherry.
The participants for the study were children aged between 6 to 12 years attending Paediatric outpatient Department. This study was conducted for a period from July 2018 to December 2018. The study protocol and procedures were approved by the Research Ethics Committee of Sri Lakshmi Narayana Institute of Medical sciences hospital, Osudu, Puducherry affiliated to Bharath University. After obtaining informed consent from the parents of the children and assuring full confidentiality to the participants, data was collected.

\section{Inclusion Criteria}

Children both boys and girls, aged 6 to 12 years attending Paediatric outpatient Department of Sri Lakshmi Narayana Institute of Medical Sciences Hospital were included in the study.

\section{Exclusion Criteria}

Children with chronic major illness as well as those on corticosteroid therapy, children with severe acute malnutrition, failure to thrive, underweight and children whose parents refused to give consent were excluded from the study.

\section{Data Collection}

The participants were about 3081 children. Informed written consent was obtained from the parents of the children. Data was collected on age, sex, and socioeconomic status, intake of junk foods, physical activity and parental obesity. A questionnaire regarding age, gender, socioeconomic status, parents' profession, intake of junk foods, physical activity, parents BMI was distributed, and information was obtained.

Socioeconomic status was assessed by Modified Kuppuswamy classification. ${ }^{17}$ Physical parameters such as height, weight and waist/hip ratio were measured using standard procedure and BMI was calculated. Height was measured barefoot, to the nearest of $0.1 \mathrm{~cm}$ using a standard calibrated bar. Weight was measured without any footwear with minimal clothing to the nearest of $0.1 \mathrm{~kg}$ using a standard portable weighing machine and weight was recorded in kilograms. IAP BMI charts were used for calculating BMI. After calculating the BMI, the values are plotted on the IAP gender specific percentile chart 2015 and BMI status of the children was assessed.

Socioeconomic status assessed by Modified Kuppuswamy classification is as follows:

\begin{tabular}{|c|c|c|}
\hline Sl. No. & Occupation of the Head of the Family & Score \\
\hline 1 & Legislators, senior officials \& mangers & 10 \\
\hline 2 & Professionals & 9 \\
\hline 3 & Technicians and associate professionals & 8 \\
\hline 4 & Clerks & 7 \\
\hline 5 & Skilled workers and shop \& market sales workers & 6 \\
\hline 6 & Skilled agricultural \& fishery workers & 5 \\
\hline 7 & Craft \& related trade workers & 4 \\
\hline 8 & Plant \& machine operators and assemblers & 3 \\
\hline 9 & Elementary occupation & 2 \\
\hline 10 & Unemployed & 1 \\
\hline \multicolumn{2}{|c|}{ Occupation of the Head of the Family } \\
\hline
\end{tabular}




\begin{tabular}{|c|c|c|}
\hline Sl. No. & Education of Head of the Family & Score \\
\hline 1 & Profession or honours & 7 \\
\hline 2 & Graduates & 6 \\
\hline 3 & Intermediate or diploma & 5 \\
\hline 4 & High school certificate & 4 \\
\hline 5 & Middle school certificate & 3 \\
\hline 6 & Primary school certificate & 2 \\
\hline 7 & Illiterate & 1 \\
\hline \multicolumn{3}{|c|}{ Education of Head of Family } \\
\hline
\end{tabular}

\begin{tabular}{|c|c|c|}
\hline Sl. No. & Updated Monthly Family Income in Rupees (2019) & Score \\
\hline 1 & $\geq 78,063$ & 12 \\
\hline 2 & $39,033-78,062$ & 10 \\
\hline 3 & $29,200-39,032$ & 6 \\
\hline 4 & $19,516-29,199$ & 4 \\
\hline 5 & $11,708-19,515$ & 3 \\
\hline 6 & $3,908-11,707$ & 2 \\
\hline 7 & $\leq 3907$ & 1 \\
\hline \multicolumn{2}{|c|}{ Total Monthly Income of Family } \\
\hline
\end{tabular}

\begin{tabular}{|c|c|c|}
\hline Sl. No. & Score & Socioeconomic Status \\
\hline 1 & $26-29$ & UPPER(1) \\
\hline 2 & $16-25$ & UPPER MIDDLE (2) \\
\hline 3 & $11-15$ & LOWER MIDDLE (3) \\
\hline 4 & $5-10$ & UPPER LOWER (4) \\
\hline 5 & $<5$ & LOWER(5) \\
\hline \multicolumn{2}{|c|}{ Kuppuswamy Socio Economic Status Scale 2019 } \\
\hline
\end{tabular}

\section{RESULTS}

A total of 3081 children were studied, out of which 93 boys and 87 girls were found to be obese. In our study, prevalence of obesity is more with lower middle class of modified Kuppuswamy scale with a significant $p$ value of 0.005 (Table 1). There was a significant prevalence of obesity with less physical activity with significant $\mathrm{p}$ value of 0.015 (Table 2).Our study also shows that prevalence of obesity is more in children, who consumed junk foods more than 4 days a week with a significant $p$ value 0.0001 (Table 3 ). There is also a significant increase in prevalence of obesity in children of obese parents than non-obese parents with $p$ value of 0.0001(Table 4).

\begin{tabular}{|c|c|c|c|}
\hline Socio Economic Class & Non-Obese & Obese & p \\
\hline Upper(I) & $6(0.2 \%)$ & $3(1.7 \%)$ & \\
Upper Middle(II) & $928(31.9 \%)$ & $91(50.56 \%)$ & \multirow{2}{*}{0.005} \\
Lower Middle(III) & $1682(58 \%)$ & $76(42.2 \%)$ & \\
\cline { 1 - 3 } Upper Lower (IV) & $245(8.4 \%)$ & $7(3.9 \%)$ & \\
Lower(V) & $40(1.4 \%)$ & $3(1.7 \%)$ & \\
\cline { 1 - 2 } Table 1. Relationship Between Obesity in Children and Socio-Economic \\
Status of Family Based on Modified Kuppuswamy Scale \\
\hline
\end{tabular}

\begin{tabular}{|c|c|c|c|}
\hline $\begin{array}{c}\text { Physical Activity for } \\
\text { Number of Days Per Week }\end{array}$ & $\begin{array}{c}\text { Obese/ } \\
\text { Overweight }\end{array}$ & $\begin{array}{c}\text { Normal/ } \\
\text { Underweight }\end{array}$ & $\mathbf{p}$ \\
\hline$>4$ days & $54(30 \%)$ & $1564(54.9 \%)$ & \multirow{2}{*}{0.015} \\
\hline$\leq 4$ days & $126(70 \%)$ & $1337(45.1 \%)$ & \\
\hline
\end{tabular}

\begin{tabular}{|c|c|c|c|c|}
\hline $\begin{array}{c}\text { Intake of Junk Food } \\
\text { (No. of Days/ } \\
\text { Week) }\end{array}$ & $\begin{array}{c}\text { BMI Category } \\
\text { Underweight/ } \\
\text { Normal }\end{array}$ & $\begin{array}{l}\text { BMI Category } \\
\text { Obese/ } \\
\text { Overweight }\end{array}$ & Total & $\mathbf{p}$ \\
\hline$>4$ days & $652(50 \%)$ & $652(50 \%)$ & 1304 & \multirow{2}{*}{0.0001} \\
\hline$\leq 4$ days & $1333(75.01 \%)$ & $444(24.99 \%)$ & 1777 & \\
\hline \multicolumn{5}{|c|}{ Table 3. Association of Intake of Junk Food with BMI } \\
\hline
\end{tabular}

\begin{tabular}{|c|c|c|c|c|}
\hline \multicolumn{2}{|c|}{ Obese Parents 2158 (70.04\%) } & \multicolumn{2}{|c|}{ Non-Obese Parents 423 (29.95\%) } & $\mathbf{p}$ \\
\hline \begin{tabular}{|c|}
$\begin{array}{c}\text { Non obese } \\
\text { Children }\end{array}$ \\
\end{tabular} & $\begin{array}{c}\text { Obese } \\
\text { Children }\end{array}$ & $\begin{array}{c}\text { Non-Obese } \\
\text { Children }\end{array}$ & \begin{tabular}{l|l} 
Obese \\
Children
\end{tabular} & \multirow[t]{2}{*}{0.0001} \\
\hline $967(33.3 \%)$ & $120(66.7 \%)$ & $967(66.7 \%)$ & $60(33.3 \%)$ & \\
\hline \multicolumn{5}{|c|}{$\begin{array}{l}\text { Table 4. Relationship between Parental Obesity and Child Obesity } \\
\qquad(N=3081)\end{array}$} \\
\hline
\end{tabular}

\section{DISCUSSION}

In our study, Prevalence of obesity is more with lower middle class of modified Kuppuswamy scale in comparison to the study done by Mandal A et al, ${ }^{18}$ Cherian AT et al. ${ }^{19}$ Our study results were in contrast with the studies done by Goyal et $\mathrm{al}^{20}$ from Gujarat, that the prevalence of obesity is higher in upper socioeconomic status group as compared to middle socioeconomic status group.

There was a significant increase in prevalence of obesity among children with less physical activity than the children with more physical activity in our study, which is supported by studies done by Ann Smith et $\mathrm{al}^{21}$ in Texas and Aggarwa et $\mathrm{a}^{22}$ proving the relationship between sedentary lifestyle and obesity. Similar results of high risk of being obese among children lacking physical activities were reported in studies done by Kumar et al, ${ }^{23}$ Kotian et al ${ }^{24}$ and Rajaat Vohra et al. ${ }^{25}$

In our study, there was a significant association between junk food intake and obesity. Children, who consumed junk foods greater than 4 days a week, had greater chance of obesity than children who consumed junk foods less than 4 days a week. Our results correlated well with the previous reports that junk food intake tends to be more common among overweight and obese adolescents than normal weight adolescents done by Klesges et al, ${ }^{26}$ Wolfe et al, ${ }^{27}$ Guven et $\mathrm{al}^{28}$ Jeffery et al. ${ }^{29}$

There was also a significant association between parental obesity and their children being obese. Our results are supported with the previous study which suggested that family history of obesity have more prevalence to obesity than family history of Diabetes done by King et al. ${ }^{30}$

\section{CONCLUSIONS}

In our study, we found out that the prevalence of obesity among children in the age group of 6 to 12 years is relatively high due to sedentary lifestyle, intake of junk foods and parental obesity. Since obesity is now becoming a very important non-communicable disease which leads to higher morbidity, steps should be taken to prevent the disease by creating awareness about the disease both in children as well as in their parents. The CATCH study (Child and Adolescent Trial for Cardiovascular Health) in multiracial American school children and 'Go Girls' community based study in African American girls, showed that children can be taught to eat less fat and exercise more. 31,32 WHO recommends at least 30 minutes of cumulative moderate exercise (equivalent to walking briskly) for all ages; plus for children, an additional 20 minutes of vigorous exercise (equivalent to running), three times a week. ${ }^{33}$ These recommendations are basically for prevention of obesity and its co-morbidities. Hence, obesity prevention awareness program should be conducted in schools and lifestyle modification should be reinforced in 
children as well as in their parents in order to prevent complications of obesity like type II diabetes, hypertension and cardiovascular diseases. It is important to teach the children to follow healthy eating habits and educate them about the importance of physical exercise since childhood.

\section{REFERENCES}

[1] World Health Organization (WHO). Preventing and managing the global epidemic Report of a WHO Consultation. Technical Reports Series No. 894. Geneva. WHO, 1997.

[2] Stigler MH, Arora M, Dhavan P, et al. Weight related concerns and weight control behaviors among overweight adolescents in Delhi, India: a cross-sectional study. Int J Behav Nutr Phys Act 2011;8:9.

[3] Popkin BM, Doak CM. The obesity epidemic is a worldwide phenomenon. Nutr Rev 1998;56(4 Pt 1):10614.

[4] Must A, Jacques PF, Dallal GE, et al. Long term morbidity and mortality of overweight adolescents: a follow up of Harvard Growth study of 1922-1935. N Eng J Med 1992;327(19):1350-5.

[5] Jo H, Trowbridge FL. Symposium on the causes and health consequence of obesity in children and adolescents. Paediatrics 1998;101:S497-574.

[6] Hoffmans MDAF, Kromhout D, de Lezenne CC. The impact of body mass index of 78,612 18-year old Dutch men on 32-year mortality from all causes. J Clin Epidemiol 1988;41(8):749-56.

[7] World Health Organization. Obesity: preventing and managing the global epidemic. Report of a WHO consultation. WHO Technical Report series, No. 894. WHO: Geneva, 2000.

[8] Butte NF, Gregorich SE, Tschann JM, et al. Longitudinal effects of parental, child and Neighborhood factors on moderate-vigorous physical activities and sedentary time in Latino children. Int J Behav Nutr Phys Act 2014;11(1):108.

[9] Gibson LY, Byrne SM, Davis EA, et al. The role of family and maternal factors in childhood obesity. Med J Aust 2007;186(11):591-5.

[10] Maffeis C, Talamini G, Tato L. Influence of diet, physical activity and parents' obesity on children's adiposity: a four-year longitudinal study. Int J Obes Relat Metab Disord 1998;22(8):758-64.

[11] Whitaker RCI, Wright JA, Pepe MS, et al. Predicting obesity in young adulthood from childhood and parental obesity. N Engl J Med 1997;337(13):869-73.

[12] Bralic I, Vrdoljak J, Kovacic V. Associations between parental and child overweight and obesity. Coll Antropol 2005;29(2):481-6.

[13] Whitaker RC, Deeks CM, Baughcum AE, et al. The relationship of childhood adiposity to parent body mass index and eating behavior. Obes Res 2000;8(3):234-40.

[14] Elder JP, Arredondo EM, Campbell N, et al. Individual, family and community environmental correlates of obesity in Latino Elementary school children. J Sch Health 2010;80(1):20-30, quiz 53-5.
[15] Janssen I, Leblanc AG. Systematic review of the health benefits of physical activity and fitness in school aged children and youth. Int J Behav Nutr Phys Act 2010;7:40.

[16] LeBlanc AGI, Spence JC, Carson V, et al. Systematic review of sedentary behavior and health indicators in early years (aged 0-4 years). Appl Physiol Nutr Metab 2012;37(4):753-72.

[17] Park K. Preventive and social medicine. Jabalpur: Banarasidas Bhanot Publishers 2015: p. 690.

[18] Mandal A, Mandal GC. Prevalence of overweight and obesity among the urban adolescents English medium school girls of Kolkata, India. Italian J Public Health 2012;9(3):1-5.

[19] Cherian AT, Cherian SS, Subbiah S. Prevalence of obesity and overweight in urban school children of Kerala, India. Indian Paediatr 2012;49(6):475-7.

[20] Goyal RK, Shah VN, Saboo BD, et al. Prevalence of overweight and obesity in Indian adolescent school going children: its relationship with socioeconomic status associated lifestyle factors. J Assoc Physicians India 2010;58:151-8.

[21] Barnes AS. Obesity and sedentary lifestyles: risk for cardiovascular disease in women. Texas Heart Institute Journal 2012;39(2):224-7.

[22] Aggarwal T, Bhatia RC, Singh RC, et al. Prevalence of obesity and overweight in affluent adolescents from Ludhiana, Punjab. Indian Paediatrics 2008;45(6):500-2.

[23] Kumar S, Mahabalaraju DK, Anuroopa MS. The prevalence of obesity and its influencing factor among affluent school children of Davangerecity. Ind J Community Med 2007;32(1):15-7.

[24] Kotian MS, Ganeshkumar S, Kotian SS. Prevalence and Determinants of overweight and obesity among adolescent school children of south Karnataka, India. Ind J Community Med 2010;35(1):176-8.

[25] Vora R, Bharadwaj P, Shrivastava JP, et al. Overweight and obesity among school-going children in Lucknow city. J Family Community Med 2011;18(2):59-62.

[26] Klesges RC, Klesges LM, Eck LH, et al. A longitudinal analysis of accelerated weight gain in preschool children. Paediatrics 1995;95(1):126-30.

[27] Wolfe WS, Campbell CC, Frongillo EA Jr, et al. Overweight schoolchildren in New York State: prevalence and characteristics. Am J Public Health 1994;84(5):807-13.

[28] Guven A, Odaci H, Ozgen IT, et al. Effect of individual factors adolescent obesity: Study in Turkey. Paediatr Int 2008;50(3):356-62.

[29] Jeffery RW, Baxter J, McGuire M, et al. Are fast food restaurants an environmental risk factor for obesity? Int J Behav Nutr Phys Act 2006;3:2.

[30] King H, Fitch C, Collins A, et al. Glucose tolerance in Papua New Guinea: ethnic difference associated with environmental and behavioral factors and the possible emergence of glucose intolerance in highland community. Med J Aust 1989;151(4):204-10.

[31] Luepker RV, Perry CL, McKinlay SM, et al. Outcomes of a field trial to improve childrens dietary patterns and physical activity. CATCH collaborative group. JAMA 1996;275(10):768-76. 
[32] Resnicow K, Yaroch AL, Davis A, et al. GO GIRLS! Results from a pilot nutrition and physical activity program for low-income, overweight, African American Adolescent Females. Health Edu Behav 2000;27(5):616-31.
[33] World Health Organisation. Annual global move for health initiative. A Concept paper. WHO, Geneva. 2003. 